\title{
Miracles in My Time: Reflections of a Paediatric Respiratory Physician.
}

\author{
John Massie ${ }^{1}$ \\ ${ }^{1}$ Royal Children's Hospital
}

July 7, 2021

\begin{abstract}
Miracles, like London buses, just seem to come along. The truth is, there are no miracles, just lots of hard work behind the scenes, minds open to opportunity, serendipity and possibly a little luck. In my time as a paediatric respiratory physician, I have born witness to remarkable advances in treatment that have changed patients' fortunes overnight. Examples of these include artificial surfactant replacement for premature newborns, conjugate haemophilus influenzae type b vaccination, propranolol for infants with subglottic haemangiomas, mandibular distraction for babies with micrognathia, cystic fibrosis transmembrane conductance regulator modulators therapy for patients with cystic fibrosis and antisense oligonucleotide therapy for infants with spinal muscular atrophy. There are lessons to be learned from reflection upon these life transforming treatments, and perhaps it is a good time just to pause and wonder.
\end{abstract}

\section{Miracles in My Time: Reflections of a Paediatric Respiratory Physician.}

John Massie, 1,2,3,4

1. Children's Bioethics Centre, Royal Children's Hospital, Melbourne

2. Department of Respiratory Medicine, Royal Children's Hospital, Melbourne

3. Department of Paediatrics, University of Melbourne

4. Murdoch Children's Research Institute, Melbourne

There are no conflicts of interest

Correspondence

Prof John Massie

Children's Bioethics Centre

Royal Children's Hospital

50 Flemington Road. Parkville. 3052. Victoria. Australia

Ph: 61393455818

Fax: 61393459154

Email: john.massie@rch.org.au

Key Words: miracles, respiratory medicine, paediatrics

There was no funding received for this manuscript.

There are no conflicts of interest. 


\section{Hosted file}

Final Miracles in My Time 23.6.21.docx available at https://authorea.com/users/424266/ articles/529400-miracles-in-my-time-reflections-of-a-paediatric-respiratory-physician 